\title{
Conservative Non-intervention Approach for Hemodynamically Significant Patent Ductus Arteriosus in Extremely Preterm Infants
}

\author{
Se In Sung ${ }^{\dagger}$, Yun Sil Chang ${ }^{\dagger}$, So Yoon Ahn, Heui Seung Jo, Misun Yang and \\ Won Soon Park* \\ Department of Pediatrics, Samsung Medical Center, Sungkyunkwan University School of Medicine, Seoul, South Korea
}

\section{OPEN ACCESS}

Edited by:

Hannes Sallmon,

Charité - Universitätsmedizin

Berlin, Germany

Reviewed by:

Fuat Emre Canpolat,

Ministry of Health, Turkey

Joseph Y. Ting,

University of British Columbia, Canada

Dany Weisz,

University of Toronto, Canada

*Correspondence:

Won Soon Park

wonspark@skku.edu

${ }^{\dagger}$ These authors have contributed equally to this work and share first

authorship

Specialty section:

This article was submitted to

Neonatology,

a section of the journal

Frontiers in Pediatrics

Received: 11 September 2020 Accepted: 07 December 2020

Published: 23 December 2020

Citation

Sung SI, Chang YS, Ahn SY, Jo HS,

Yang $M$ and Park WS (2020)

Conservative Non-intervention

Approach for Hemodynamically Significant Patent Ductus Arteriosus in

Extremely Preterm Infants.

Front. Pediatr. 8:605134.

doi: 10.3389/fped.2020.605134
While persistent patent ductus arteriosus (PDA) in preterm infants has been known to be associated with increased mortality and morbidities including bronchopulmonary dysplasia, and necrotizing enterocolitis, there is minimal evidence supporting their causal relationships, and most traditional medical and/or surgical treatments have failed to show improvements in these outcomes. As such, the pendulum has swung toward the conservative non-intervention approach for the management of persistent PDA during the last decade; however, the benefits and risks of this approach are unclear. In this mini review, we focused on whom, when, and how to apply the conservative non-intervention approach for persistent PDA, especially in extremely preterm infants.

Keywords: patent ductus arteriosus, premature infants, extremely preterm infants, conservative management, non-intervention

\section{INTRODUCTION}

Persistent patent ductus arteriosus (PDA) in premature infants has been known to be associated with increased mortality and morbidities including bronchopulmonary dysplasia (BPD), and necrotizing enterocolitis (NEC) (1-3); however, there is minimal evidence to support their causal relationship (3-5). Although it is traditional to manage PDA with nonsteroidal anti-inflammatory agents such as indomethacin, ibuprofen and recently acetaminophen (6), and/or surgical ligation, definite evidence supporting the benefits of these therapies over the conservative non-intervention approach is lacking (7-9), and they may even be associated with adverse effects (10-14). As such, the pendulum has swung toward the conservative non-intervention approach for managing hemodynamically significant (HS) PDA in preterm infants over the last decade $(15,16)$. However, the risks and benefits of the conservative non-intervention approach still remain unclear with variable outcomes showing no effect $(17-19)$, reducing $(16,20)$ or increasing bronchopulmonary dysplasia (BPD) incidence, or death compared with traditional medical/surgical therapies $(9,21)$. These controversial outcomes of the conservative non-intervention approach may be attributable to confounding PDA treatment indications or disease severity $(16,17,19)$, bias of non-independent sampling $(16,17)$, or lack of patient stratification according to gestational age $(9,16,21)$. In this mini review, we focused on identifying those indicated for treatment, its optimal timing, and the method of applying the conservative non-intervention approach for HS PDA especially in extremely preterm infants (EPTs). 


\section{CONSERVATIVE NON-INTERVENTION APPROACH}

\section{Rationale for the Conservative Non-intervention Approach for HS PDA}

The rationale of a mandatory closure approach with medical and/or surgical treatment for HS PDA is based on the deeply ingrained hypothesis that large left-to-right shunting via PDA directly causes increased mortality and morbidities (2, 22-25). The closure rate of HS PDA after treatment with cyclooxygenase inhibitors was inversely proportional to gestational age (GA), being as low as $29 \%$ in EPTs with GA of 23-26 weeks (20, 26-29); and ultimately, $>72 \%$ received ductal ligation even with a more conservative approach for treating PDA in these infants not responding to medical treatment $(20,30)$. However, there is a possibility that the detrimental effects of surgical ligation may outweigh the benefits derived from PDA closure $(11,31,32)$. Moreover, although prolonged exposure to large left-to-right shunting via HS PDA may increase the risk of mortality and morbidities (9, 33-37), no significant differences in mortality and morbidities such as NEC and IVH and even significantly lower incidences of BPD were observed with the conservative non-intervention approach compared with the mandatory closure approach in our previous retrospective study (20). In our recently conducted prospective double-blind randomized controlled trial (RCT) that directly compared the therapeutic efficacy of exclusive pharmacologic treatment with the standard dose of oral ibuprofen-mediated PDA closure and a non-intervention approach with few backup treatments (38), oral ibuprofen treatment significantly promoted the ductal closure rate at 1 week after randomization in the 27-30-week but not in the 23-26-week GA subgroup compared to the nonintervention approach, but the ultimate ductal closure rate and incidence of BPD/death were not significantly different between the two study groups. Recent studies have suggested that highdose ibuprofen has better efficacy especially when used later, though data among micro-premature infants is lacking (39, 40). Considering the postnatal rise of serum creatinine levels indicative of low glomerular filtration rate due to immature nephrogenesis peaking at postnatal day 10 and 14 in EPTs at 23-24 and 25-26 weeks' gestation (41), standard rather than high dose oral ibuprofen therapy at first postnatal weeks was pharmacokinetically more ideal in the EPTs (40). The noninferiority of non-intervention approach was partly attributable to the low response rate of standard-dose ibuprofen especially in EPTs at 23-26 weeks' gestation. However, considering the high ultimate treatment failure rate of 71 and $62 \%$ even with repeated doses of intravenous indomethacin and ibuprofen in the infants at 23-26 and 23-25 weeks' gestation (20,26), our data of low response rate of oral ibuprofen for PDA closure in the infants at 23-26 but not at 27-30 weeks' gestation might be more attributable to younger gestational age of study population rather than to low therapeutic efficacy of oral ibuprofen therapy for closing PDA. Moreover, our data of $89-82 \%$ PDA closure rates before discharge in the ibuprofen and non-intervention arms with virtually no backup treatment, were much higher than the previously known overall PDA closure rate of $67 \%$ with medical treatment in premature infants (39). Our data showed a relatively lower $44 \% \mathrm{BPD} /$ death rate in the nonintervention arm with virtually no backup treatment compared to that of PDA TOLERATE trial showing a $57 \% \mathrm{BPD} /$ death rate with ligation rate of $12 \%$ in the conservative approach arm. Altogether, a current lack of definite evidence showing therapeutic benefits of traditional medical/surgical therapies over conservative treatment with supportive care endorse the conservative non-intervention approach allowing spontaneous closure as an alternative management option to the mandatory closure approach for HS PDA in EPTs (3, 4, 7, 20, 38, 42-44).

\section{Who Is Indicated for the Conservative Non-intervention Approach?}

While a staging system assessing the magnitude of HS PDA based on clinical, biochemical, and echocardiographic criteria has been proposed $(13,45,46)$, a clear definition of PDA shunt size and clinical illness severity eligible for the conservative nonintervention approach in preterm infants with persistent PDA is still lacking because of the paucity of available data for this approach $(9,11,47-51)$. Moreover, practical difficulties exist in quantifying the shunt volume to distinguish which PDA are truly symptomatic (46). Discerning the hemodynamic significance of preterm PDA is challenging and should incorporate the echocardiographic measurements to assess the magnitude of ductal shunt volume, and the parameters reflecting the impact of shunt volume on end-organ systems. Therefore, the meaning of HS PDA may vary from one another in the clinical studies. Future studies about defining the hemodynamic significance of PDA should focus on the clinical outcomes rather association with the shunt volume (1). In the PDA-TOLERATE (PDATO Leave it alone or Respond And Treat Early) RCT (4), the enrollment criterion for HS PDA was defined as moderate-tolarge PDA with a ductal size $>1.5 \mathrm{~mm}$ and predominant leftto-right shunt in EPTs (GA $<28$ weeks) with respiratory failure requiring assisted respiratory support. However, this trial had significant selection bias as $40 \%$ of potentially eligible EPTs were not recruited, and received active treatment outside the PDATOLERATE trial because of "lack of physician equipoise"(52). Moreover, this trial was also confounded by a high backup rescue treatment rate of $48 \%$, with $12 \%$ of patients receiving PDA ligation even in the conservative treatment arm (4). In our neonatal intensive care unit (NICU), we first introduced the conservative non-intervention approach in EPTs $(\mathrm{GA}<27$ weeks) who did not require early ventilator support regardless of PDA size $(9,47,49)$. After confirming the tolerability of this approach without adverse effects, we switched the policy for the management of severe HS PDA (PDA size $>2 \mathrm{~mm}$ requiring mechanical ventilator support with symptoms/signs suggestive of PDA) in EPTs (GA = 23-26 weeks) from a mandatory PDA closure approach with indomethacin and/or surgical ligation to a conservative non-intervention approach without pharmacological/surgical treatments (20). Our results showed that the non-intervention approach was associated with less BPD compared with mandatory closure approach. Although backup medical/surgical treatment was available at the 
attending neonatologist's discretion, no EPT managed with the conservative non-intervention approach for HS PDA received backup treatment. However, the comparison of outcomes in the epoch-based study can be biased by the improvement of global care throughout the study period. Our data showing improved BPD rate without any significant differences in mortality or other morbidities between the two study periods might support the benefits of non-intervention over the mandatory closure, probably attributable to the avoidance of surgical ligation rather than to improved global care. In our recently conducted double-blind RCT (38), only EPTs with symptomatic PDA requiring respiratory support (average PDA size of $2.5 \mathrm{~mm}$ and left atrium/aorta ratio of 1.61 compatible with moderate-tosevere clinical and echocardiographic severity) were enrolled in the non-intervention arm, and received no backup treatment. Furthermore, as conservative non-intervention approach has become a standard treatment for HS PDA in EPT since 2012 (20), and all the EPTs not enrolled in our RCT were exclusively managed with conservative non-intervention approach with virtually no rescue treatment (38). Overall, these findings suggest that all EPTs, even those with the most severe HS PDA, could be indicated for management with the conservative non-intervention approach regardless of the clinical and echocardiographic severity.

\section{What Is the Optimal Timing for the Conservative Non-intervention Approach?}

Determining the optimal timing of the mandatory closure approach with medical/surgical treatment or conservative nonintervention approach for managing HS PDA in EPTs is a critical issue in clinical settings. As the PDA may close spontaneously even in EPTs $(19,53-55)$, we avoided unnecessary treatment exposure in $37 \%$ of eligible patients by delaying their enrollment for approximately 1 week in our recently conducted RCT (38). However, there is a concern that delaying the pharmacologic PDA treatment up to the first postnatal week may increase mortality or morbidities $(5,52,56,57)$. In a prospective doubleblind RCT of eligible infants $<29$ weeks' gestation, Kluckow et al. observed that early indomethacin treatment of a large PDA in patients under $12 \mathrm{~h}$ of age reduced pulmonary hemorrhage (PH) from 21 to $2 \%$, IVH from 12.5 to $4.5 \%$, and later backup treatment of PDA from 40 to $20 \%$, but had no effect on the primary outcome of death or abnormal cranial ultrasound (55). In contrast, in our RCT, the incidences of IVH in oral ibuprofen and non-intervention arms were 3 and 6\%, respectively; and there was no $\mathrm{PH}$ in both arms (38). These findings suggest that prophylaxis alone is not enough for better therapeutic outcome of HS PDA, and that just applying the conservative non-intervention approach alone also is not enough, but the accompanying meticulous neonatal intensive care is essential for the success of this approach $(20,38,41,54)$. The meticulous care starting from better delivery room management at birth includes judicious fluid restriction with high humidification to avoid volume overload and the ensuing congestive heart failure, ventilatory strategies to minimize pulmonary over-circulation including less oxygen use, and strict infection control practices, which will be discussed in detail later in section How to Apply the Conservative Non-intervention Approach? As the prevalence of HS PDA at 1 week after birth is inversely proportional to GA $(93,64$, and $21 \%$ in EPTs with GA of 23-24, 25-26, and 27-28 weeks, respectively) (54), the lack of stratification according to GA may be the primary factor responsible for the controversial inconsistent outcomes of delaying PDA treatment until the first postnatal week $(9,21,58)$. Collectively, these findings suggest that there is no critical therapeutic time window for the beneficial therapeutic efficacy of traditional pharmacologic/surgical treatment, and that the accompanying meticulous neonatal intensive care starting from birth is prerequisite for the success of the conservative non-intervention approach for HS PDA in EPTs (3, 20, 38, 41, 43, 44, 54).

Recently, neonatologist performed echocardiography (NPE) has been proposed as an instrumental diagnostic tool for early screening of HS PDA (59). However, as noted by the recommendation of the European Society for Pediatric Research and European Society for Neonatology (60), care should be taken against the indiscriminate application without considerable skill and experience. Frequent examination of the babies in the early critical period of life may have a hazardous effect on the patient safety; the lack of good repeatability of the echocardiographic measurements and the misinterpretation of those parameters can lead to overtreatment for PDA that can mostly close spontaneously without increasing neonatal morbidities. Further studies are needed to evidence the feasibility and the robustness of NPE.

\section{Natural Course of HS PDA With the Conservative Non-intervention Approach}

Owing to the traditional mandatory closure approach of HS PDA with medical and/or surgical treatment at the earliest time based on the old dogma that adverse outcomes are proportional to the magnitude and duration of left-to-right ductal shunting $(2,61)$, and the high backup treatment rates even with the conservative non-intervention approach for $\operatorname{HS}$ PDA $(4,52,55)$, few studies have chronologically monitored the natural history of HS PDA in EPTs. Rolland et al. observed a $73 \%$ spontaneous closure rate in EPTs with $<28$ weeks' gestation without specific treatment aimed to close PDA (62). Semberova et al. reported an $85 \%$ spontaneous PDA closure rate before hospital discharge in very low birth weight infants who received truly conservative PDA management (63). In our previous study, only 3\% of EPTs with GA of 23-28 weeks with HS PDA solely managed with a conservative noninterventional approach patients were discharged home without ductal closure, $2 \%$ had spontaneous closure on outpatient followup, and $1 \%$ received device closure (54). Overall, these findings suggest that spontaneous closure of HS PDA could be achieved solely with conservative non-interventional management even in EPTs near the limit of viability, and that exposure to the risks of medical/surgical therapeutic interventions targeted for ductal closure may not be warranted in these infants.

Despite the current lack of evidence supporting the causal relationships between a large left-to-right shunt via HS PDA and mortality/morbidities, significant associations between large 
PDA shunt volumes and morbidities such as BPD were observed in some studies $(1,13,45,64)$. In contrast, the presence of HS PDA was not associated with increased mortality or morbidities such as severe IVH, BPD, NEC, acute kidney injury, retinopathy of prematurity, and sepsis compared with EPTs without HS PDA $(41,54,65)$. Besides the magnitude, the prolonged duration of large left-to-right shunting via PDA may be an important cause of mortality and/or morbidities. Shena et al. reported that each week of HS PDA increased the risk of developing BPD in EPTs with $<28$ weeks' gestation by 1.7 times, and a prolonged PDA with later surgical ligation (33 vs. 23 days) was associated with increased death or BPD (51). In contrast, we previously showed a significantly lower incidence of BPD and comparable mortality despite significantly delayed closure of HS PDA at postnatal day 44 with a conservative non-intervention approach compared with earlier mandatory closure with medical/surgical treatments at postnatal day 13 in EPTs with GA of 23-26 weeks (20). Moreover, while the mean closure time of HS PDA was inversely proportional to GA (P53, P41, and P36 in EPTs with GA of 23-24, 25-26, and 27-28 weeks, respectively), a prolonged duration per week of HS PDA with a conservative non-intervention approach was not associated with increased mortality and/or morbidities in multivariate analyses adjusted for GA and birth weight (54). Despite the limitation of the previous studies including the retrospective nature of the study design, the seeming association between the presence and prolonged duration of HS PDA and mortality/morbidities may be primarily attributable to immaturity itself, and our data showing a favorable outcome of the conservative non-interventional approach for HS PDA in EPTs at least support the safety and feasibility of this approach over traditional medical/surgical treatments for managing HS PDA in EPTs (20).

\section{How to Apply the Conservative Non-intervention Approach?}

As excessive fluid intake increased the risk of HS PDA and the ensuing congestive heart failure (66-68), the reasons why prolonged exposure to HS PDA with the conservative nonintervention approach did not increase mortality/morbidities in our previous studies may be primarily attributable to judicious fluid restriction $(20,30,38,54)$. In order to achieve judicious fluid restriction, restricting the first-day fluid intake to as low as $60 \mathrm{ml} / \mathrm{kg} /$ day even in peri-viable EPTs with GA of 23-24 weeks must be accompanied by meticulous neonatal intensive care including better delivery room management with extreme caution of fragile skin care, minimal handling, and high humidification during the first several postnatal days $(69,70)$. We individualized and adjusted the daily target fluid volume for each EPT after assessment of the volume status by monitoring the urine output and specific gravity, body weight, serum electrolytes, and estimating the insensible water loss (41). Due to the greater and delayed peak of serum creatinine levels during the first few postnatal weeks in EPTs, indicative of low glomerular filtration, we tried to avoid fluid overload by maintaining a low fluid intake $(<116 \mathrm{ml} / \mathrm{kg} /$ day $)$ during the first 4 postnatal weeks without restricting caloric intake or increasing the incidence of electrolyte and renal dysfunctions $(20,41,54)$. In our previous retrospective study in which we applied the same fluid policy, the incidence of hypernatremia (>150 mEq/dL sodium) was 41,21 , and $15 \%$ in 23,24 , and $\geq 25$ weeks' gestation infants (71). Taken together, these findings suggest that merely applying conservative management for HS PDA is not sufficient to achieve better clinical outcomes, and meticulous NICU care, including judicious fluid restriction, is a prerequisite for successful clinical translation of the non-intervention approach to manage HS PDA in EPTs.

While Liebowitz and Clyman reported a high incidence of HS PDA (67\%) at the first postnatal week in EPTs (mean GA $=26$ weeks) with a first-day fluid intake of $166 \mathrm{ml} / \mathrm{kg} /$ day, a much lower incidence (57\%) was reported in EPTs (mean $\mathrm{GA}=25$ weeks) with a first-day fluid intake of $67 \mathrm{ml} / \mathrm{kg} /$ day in our previous study $(21,54)$. Moreover, while Semberova et al. reported $>30 \%$ of infants with birth weights of $750-$ $999 \mathrm{~g}$ taking liberal fluid intake were discharged home with open ductus, we observed only $<10 \%$ of EPTs (GA of $23-$ 26 weeks) with restricted fluid intake of $107-115 \mathrm{ml} / \mathrm{kg} /$ day between P7-28 discharged home with open ductus in our previous studies $(19,20,38,54)$. Collectively, these findings suggest that judicious fluid restriction to avoid excessive fluid intake may be essential to reduce the prevalence of HS PDA and promote its earlier closure, thereby reducing the associated mortality/morbidities (66).

Although pro re nata diuretics were more frequently used with the conservative non-intervention approach than with the mandatory closure approach in our previous study (20), their therapeutic efficacy has not been proven in EPTs with immature tubular function (41), and furosemide may even promote continued patency of PDA (72). Inotropic support was used more frequently with the mandatory closure approach than with the conservative non-intervention approach in our previous study (20). High frequency ventilation may be effective for reducing pulmonary blood flow via PDA. Further studies are necessary to further clarify these controversial issues.

As the risk of developing BPD in EPTs with HS PDA increased substantially with concurrent bacterial sepsis (73), the implementation of clinical strategies to reduce nosocomial sepsis including reduced use of invasive procedures and antibiotics may be important for ameliorating the potential adverse effects associated with HS PDA $(74,75)$.

\section{DISCUSSION}

Recent evidences show the feasibility and the efficacy of more conservative approach in the management of PDA compared to mandatory treatment approach, resulting in lower PDA ligation rates and similar neonatal outcomes (4, 7, 30, 38). Accordingly, there was an increasing worldwide trend toward conservative management for HS PDA in preterm infants. The recently published trial suggested that the conservative non-intervention approach with virtually no backup traditional medical/surgical 
treatments could be indicated even for the most severe cases of HS PDAs regardless of its clinical and echocardiographic severity, and showed that almost all HS PDAs eventually closed spontaneously without increased mortality/morbidities even in the peri-viable EPTs (38). However, just applying conservative nonintervention approach is not enough, and meticulous neonatal intensive care including better delivery room management with extreme caution on skin care, judicious fluid restriction starting from the first day until at least 4 postnatal weeks along with minimal handling and high humidification during first several postnatal days, better infection control strategies to prevent sepsis, and less invasive assisted ventilator strategies including less use of oxygen are essential for the success of the conservative non-intervention approach for HS PDA in EPTs $(54,68,69,71,74)$. Our findings also support the need for

\section{REFERENCES}

1. El-Khuffash A, James AT, Corcoran JD, Dicker P, Franklin O, Elsayed $\mathrm{YN}$, et al. A patent ductus arteriosus severity score predicts chronic lung disease or death before discharge. J Pediatr. (2015) 167:135461.e2. doi: 10.1016/j.jpeds.2015.09.028

2. Noori S, McCoy M, Friedlich P, Bright B, Gottipati V, Seri I, et al. Failure of ductus arteriosus closure is associated with increased mortality in preterm infants. Pediatrics. (2009) 123:e138-44. doi: 10.1542/peds.2008-2418

3. Slaughter JL, Reagan PB, Newman TB, Klebanoff MA. Comparative effectiveness of nonsteroidal anti-inflammatory drug treatment vs no treatment for patent ductus arteriosus in preterm infants. JAMA Pediatr. (2017) 171:e164354. doi: 10.1001/jamapediatrics.2016.4354

4. Clyman RI, Liebowitz M, Kaempf J, Erdeve O, Bulbul A, Hakansson S, et al. PDA-TOLERATE trial: an exploratory randomized controlled trial of treatment of moderate-to-large patent ductus arteriosus at 1 week of age. $J$ Pediatr. (2019) 205:41-8.e6. doi: 10.1016/j.jpeds.2018.09.012

5. Willis KA, Weems MF. Hemodynamically significant patent ductus arteriosus and the development of bronchopulmonary dysplasia. Congenit Heart Dis. (2019) 14:27-32. doi: 10.1111/chd.12691

6. Ohlsson A, Shah PS. Paracetamol (acetaminophen) for patent ductus arteriosus in preterm or low birth weight infants. Cochrane Database Syst Rev. (2018) 4:CD010061. doi: 10.1002/14651858.CD010061.pub3

7. Benitz WE. Treatment of persistent patent ductus arteriosus in preterm infants: time to accept the null hypothesis? J Perinatol. (2010) 30:24152. doi: $10.1038 /$ jp. 2010.3

8. Bose CL, Laughon MM. Patent ductus arteriosus: lack of evidence for common treatments. Arch Dis Child Fetal Neonatal Ed. (2007) 92:F498502. doi: 10.1136/adc.2005.092734

9. Kaempf JW, Wu YX, Kaempf AJ, Kaempf AM, Wang L, Grunkemeier G. What happens when the patent ductus arteriosus is treated less aggressively in very low birth weight infants? J Perinatol. (2012) 32:3448. doi: $10.1038 /$ jp.2011.102

10. Chang LY, McCurnin D, Yoder B, Shaul PW, Clyman RI. Ductus arteriosus ligation and alveolar growth in preterm baboons with a patent ductus arteriosus. Pediatr Res. (2008) 63:299-302. doi: 10.1203/PDR.0b013e318163a8e4

11. Clyman RI. The role of patent ductus arteriosus and its treatments in the development of bronchopulmonary dysplasia. Semin Perinatol. (2013) 37:102-7. doi: 10.1053/j.semperi.2013.01.006

12. Mirea L, Sankaran K, Seshia M, Ohlsson A, Allen AC, Aziz K, et al. Treatment of patent ductus arteriosus and neonatal mortality/morbidities: adjustment for treatment selection bias. J Pediatr. (2012) 161:68994.e1. doi: 10.1016/j.jpeds.2012.05.007

13. Sehgal A, Paul E, Menahem S. Functional echocardiography in staging for ductal disease severity: role in predicting outcomes. Eur J Pediatr. (2013) 172:179-84. doi: 10.1007/s00431-012-1851-0 future studies to reexamine and better clarify the pros and cons of the conservative non-intervention approach for HS PDA in EPTs.

\section{AUTHOR CONTRIBUTIONS}

SS drafted and wrote the manuscript. YC and SA conceived, reviewed, and revised the manuscript. HJ and MY were involved in literature search and revised the manuscript. WP conceived, drafted, and critically revised the manuscript. All authors contributed to the article and approved the submitted version.

\section{FUNDING}

Funding for this study was provided by the 20 by 20 project from Samsung Medical Center, Best \#3, GFO3200091.

14. Teixeira LS, Shivananda SP, Stephens D, Van Arsdell G, McNamara PJ. Postoperative cardiorespiratory instability following ligation of the preterm ductus arteriosus is related to early need for intervention. J Perinatol. (2008) 28:803-10. doi: 10.1038/jp.2008.101

15. Chock VY, Goel VV, Palma JP, Luh TM, Wang NA, Gaskari S, et al. Changing management of the patent ductus arteriosus: effect on neonatal outcomes and resource utilization. Am J Perinatol. (2017) 34:9905. doi: 10.1055/s-0037-1601442

16. Lokku A, Mirea L, Lee SK, Shah PS, Canadian Neonatal N. Trends and outcomes of patent ductus arteriosus treatment in very preterm infants in Canada. Am J Perinatol. (2017) 34:441-50. doi: 10.1055/s-0036-1593351

17. Bixler GM, Powers GC, Clark RH, Walker MW, Tolia VN. Changes in the diagnosis and management of patent ductus arteriosus from 2006 to 2015 in United States neonatal intensive care units. J Pediatr. (2017) 189:10512. doi: 10.1016/j.jpeds.2017.05.024

18. Hagadorn JI, Bennett MV, Brownell EA, Payton KSE, Benitz WE, Lee HC. Covariation of neonatal intensive care unit-level patent ductus arteriosus management and in-neonatal intensive care unit outcomes following preterm birth. J Pediatr. (2018) 203:225-33.e1. doi: 10.1016/j.jpeds.2018.07.025

19. Hagadorn JI, Brownell EA, Trzaski JM, Johnson KR, Lainwala S, Campbell BT, et al. Trends and variation in management and outcomes of very lowbirth-weight infants with patent ductus arteriosus. Pediatr Res. (2016) 80:78592. doi: 10.1038/pr.2016.166

20. Sung SI, Chang YS, Chun JY, Yoon SA, Yoo HS, Ahn SY, et al. Mandatory closure versus nonintervention for patent ductus arteriosus in very preterm infants. J Pediatr. (2016) 177:66-71.e1. doi: 10.1016/j.jpeds.2016. 06.046

21. Liebowitz M, Clyman RI. Prophylactic indomethacin compared with delayed conservative management of the patent ductus arteriosus in extremely preterm infants: effects on neonatal outcomes. J Pediatr. (2017) 187:11926.e1. doi: 10.1016/j.jpeds.2017.03.021

22. Burnard ED. The cardiac murmur in relation to symptoms in the newborn. $\mathrm{Br}$ Med J. (1959) 1:134-8. doi: 10.1136/bmj.1.5115.134

23. Northway WH, Jr., Rosan RC, Porter DY. Pulmonary disease following respirator therapy of hyaline-membrane disease. Bronchopulmonary dysplasia. N Engl J Med. (1967) 276:35768. doi: 10.1056/NEJM196702162760701

24. Brooks JM, Travadi JN, Patole SK, Doherty DA, Simmer K. Is surgical ligation of patent ductus arteriosus necessary? The Western Australian experience of conservative management. Arch Dis Child Fetal Neonatal Ed. (2005) 90:F2359. doi: 10.1136/adc.2004.057638

25. Gregory GA, Kitterman JA, Phibbs RH, Tooley WH, Hamilton WK. Treatment of the idiopathic respiratory-distress syndrome with continuous positive airway pressure. N Engl J Med. (1971) 284:1333-40. doi: 10.1056/NEJM197106172842401

26. Dani C, Bertini G, Corsini I, Elia S, Vangi V, Pratesi S, et al. The fate of ductus arteriosus in infants at 23-27 weeks of gestation: from 
spontaneous closure to ibuprofen resistance. Acta Paediatr. (2008) 97:117680. doi: 10.1111/j.1651-2227.2008.00871.x

27. Koch J, Hensley G, Roy L, Brown S, Ramaciotti C, Rosenfeld CR. Prevalence of spontaneous closure of the ductus arteriosus in neonates at a birth weight of 1000 grams or less. Pediatrics. (2006) 117:111321. doi: 10.1542/peds.2005-1528

28. Nemerofsky SL, Parravicini E, Bateman D, Kleinman C, Polin RA, Lorenz JM. The ductus arteriosus rarely requires treatment in infants $>1000$ grams. Am J Perinatol. (2008) 25:661-6. doi: 10.1055/s-0028-1090594

29. Van Overmeire B, Smets K, Lecoutere D, Van de Broek H, Weyler J, Degroote K, et al. A comparison of ibuprofen and indomethacin for closure of patent ductus arteriosus. N Engl J Med. (2000) 343:67481. doi: 10.1056/NEJM200009073431001

30. Jhaveri N, Moon-Grady A, Clyman RI. Early surgical ligation versus a conservative approach for management of patent ductus arteriosus that fails to close after indomethacin treatment. J Pediatr. (2010) 157:381-7, 7.e1. doi: 10.1016/j.jpeds.2010.02.062

31. Chorne N, Leonard C, Piecuch R, Clyman RI. Patent ductus arteriosus and its treatment as risk factors for neonatal and neurodevelopmental morbidity. Pediatrics. (2007) 119:1165-74. doi: 10.1542/peds.2006-3124

32. Clyman RI, Couto J, Murphy GM. Patent ductus arteriosus: are current neonatal treatment options better or worse than no treatment at all? Semin Perinatol. (2012) 36:123-9. doi: 10.1053/j.semperi.2011.09.022

33. Chess PR, D'Angio CT, Pryhuber GS, Maniscalco WM. Pathogenesis of bronchopulmonary dysplasia. Semin Perinatol. (2006) 30:1718. doi: 10.1053/j.semperi.2006.05.003

34. Dudell GG, Gersony WM. Patent ductus arteriosus in neonates with severe respiratory disease. J Pediatr. (1984) 104:91520. doi: 10.1016/S0022-3476(84)80499-0

35. Jacob J, Gluck L, DiSessa T, Edwards D, Kulovich M, Kurlinski J, et al. The contribution of PDA in the neonate with severe RDS. J Pediatr. (1980) 96:79-87. doi: 10.1016/S0022-3476(80)80336-2

36. Martin CG, Snider AR, Katz SM, Peabody JL, Brady JP. Abnormal cerebral blood flow patterns in preterm infants with a large patent ductus arteriosus. $J$ Pediatr. (1982) 101:587-93. doi: 10.1016/S0022-3476(82)80715-4

37. McCurnin D, Seidner S, Chang LY, Waleh N, Ikegami M, Petershack J, et al. Ibuprofen-induced patent ductus arteriosus closure: physiologic, histologic, and biochemical effects on the premature lung. Pediatrics. (2008) 121:94556. doi: 10.1542/peds.2007-2051

38. Sung SI, Lee MH, Ahn SY, Chang YS, Park WS. Effect of nonintervention vs oral ibuprofen in patent ductus arteriosus in preterm infants: a randomized clinical trial. JAMA Pediatr. (2020) 174:755-63. doi: 10.1001/jamapediatrics.2020.1447

39. Mitra S, Florez ID, Tamayo ME, Mbuagbaw L, Vanniyasingam T, Veroniki AA, et al. Association of placebo, indomethacin, ibuprofen, and acetaminophen with closure of hemodynamically significant patent ductus arteriosus in preterm infants: a systematic review and meta-analysis. JAMA. (2018) 319:1221-38. doi: 10.1001/jama.2018.1896

40. Hirt D, Van Overmeire B, Treluyer JM, Langhendries JP, Marguglio A, Eisinger MJ, et al. An optimized ibuprofen dosing scheme for preterm neonates with patent ductus arteriosus, based on a population pharmacokinetic and pharmacodynamic study. Br J Clin Pharmacol. (2008) 65:629-36. doi: 10.1111/j.1365-2125.2008.03118.x

41. Seo ES, Sung SI, Ahn SY, Chang YS, Park WS. Changes in serum creatinine levels and natural evolution of acute kidney injury with conservative management of hemodynamically significant patent ductus arteriosus in extremely preterm infants at 23-26 weeks of gestation. J Clin Med. (2020) 9:699. doi: $10.3390 /$ jcm 9030699

42. Hamrick SE, Hansmann G. Patent ductus arteriosus of the preterm infant. Pediatrics. (2010) 125:1020-30. doi: 10.1542/peds.2009-3506

43. Letshwiti JB, Semberova J, Pichova K, Dempsey EM, Franklin OM, Miletin J. A conservative treatment of patent ductus arteriosus in very low birth weight infants. Early Hum Dev. (2017) 104:45-9. doi: 10.1016/j.earlhumdev.2016.12.008

44. Benitz WE. Hey, doctor, leave the PDA alone. Pediatrics. (2017) 140:e20170566. doi: 10.1542/peds.2017-0566
45. McNamara PJ, Sehgal A. Towards rational management of the patent ductus arteriosus: the need for disease staging. Arch Dis Child Fetal Neonatal Ed. (2007) 92:F424-7. doi: 10.1136/adc.2007.118117

46. Jain A, Shah PS. Diagnosis, evaluation, and management of patent ductus arteriosus in preterm neonates. JAMA Pediatr. (2015) 169:86372. doi: 10.1001/jamapediatrics.2015.0987

47. Herrman K, Bose C, Lewis K, Laughon M. Spontaneous closure of the patent ductus arteriosus in very low birth weight infants following discharge from the neonatal unit. Arch Dis Child Fetal Neonatal Ed. (2009) 94:F4850. doi: 10.1136/adc.2007.129270

48. Pietz J, Achanti B, Lilien L, Stepka EC, Mehta SK. Prevention of necrotizing enterocolitis in preterm infants: a 20-year experience. Pediatrics. (2007) 119:e164-70. doi: 10.1542/peds.2006-0521

49. Vanhaesebrouck S, Zonnenberg I, Vandervoort P, Bruneel E, Van Hoestenberghe MR, Theyskens C. Conservative treatment for patent ductus arteriosus in the preterm. Arch Dis Child Fetal Neonatal Ed. (2007) 92:F244-7. doi: 10.1136/adc.2006.104596

50. Chock VY, Punn R, Oza A, Benitz WE, Van Meurs KP, Whittemore AS, et al. Predictors of bronchopulmonary dysplasia or death in premature infants with a patent ductus arteriosus. Pediatr Res. (2014) 75:5705. doi: $10.1038 /$ pr.2013.253

51. Schena F, Francescato G, Cappelleri A, Picciolli I, Mayer A, Mosca $\mathrm{F}$, et al. Association between hemodynamically significant patent ductus arteriosus and bronchopulmonary dysplasia. J Pediatr. (2015) 166:148892. doi: 10.1016/j.jpeds.2015.03.012

52. Liebowitz M, Katheria A, Sauberan J, Singh J, Nelson K, Hassinger DC, et al. Lack of equipoise in the PDA-TOLERATE trial: a comparison of eligible infants enrolled in the trial and those treated outside the trial. J Pediatr. (2019) 213:222-6.e2. doi: 10.1016/j.jpeds.2019.05.049

53. Ngo S, Profit J, Gould JB, Lee HC. Trends in patent ductus arteriosus diagnosis and management for very low birth weight infants. Pediatrics. (2017) 139:e20162390. doi: 10.1542/peds.2016-2390

54. Sung SI, Chang YS, Kim J, Choi JH, Ahn SY, Park WS. Natural evolution of ductus arteriosus with noninterventional conservative management in extremely preterm infants born at 23-28 weeks of gestation. PLoS ONE. (2019) 14:e0212256. doi: 10.1371/journal.pone.0212256

55. Kluckow M, Jeffery M, Gill A, Evans N. A randomised placebo-controlled trial of early treatment of the patent ductus arteriosus. Arch Dis Child Fetal Neonatal Ed. (2014) 99:F99-104. doi: 10.1136/archdischild-2013-304695

56. Clyman RI. Patent ductus arteriosus, its treatments, and the risks of pulmonary morbidity. Semin Perinatol. (2018) 42:23542. doi: 10.1053/j.semperi.2018.05.006

57. Clyman RI, Hills NK, Liebowitz M, Johng S. Relationship between duration of infant exposure to a moderate-to-large patent ductus arteriosus shunt and the risk of developing bronchopulmonary dysplasia or death before 36 weeks. Am J Perinatol. (2020) 37:216-23. doi: 10.1055/s-0039-1697672

58. Cordero L, Nankervis CA, Delooze D, Giannone PJ. Indomethacin prophylaxis or expectant treatment of patent ductus arteriosus in extremely low birth weight infants? J Perinatol. (2007) 27:158-63. doi: 10.1038/sj.jp.7211659

59. van Laere D, van Overmeire B, Gupta S, El-Khuffash A, Savoia M, McNamara PJ, et al. Application of NPE in the assessment of a patent ductus arteriosus. Pediatr Res. (2018) 84:46-56. doi: 10.1038/s41390-018-0077-x

60. de Boode WP, Singh Y, Gupta S, Austin T, Bohlin K, Dempsey E, et al. Recommendations for neonatologist performed echocardiography in Europe: consensus statement endorsed by European Society for Paediatric Research (ESPR) and European Society for Neonatology (ESN). Pediatr Res. (2016) 80:465-71. doi: 10.1038/pr.2016.126

61. Gersony WM, Peckham GJ, Ellison RC, Miettinen OS, Nadas AS. Effects of indomethacin in premature infants with patent ductus arteriosus: results of a national collaborative study. J Pediatr. (1983) 102:895906. doi: 10.1016/S0022-3476(83)80022-5

62. Rolland A, Shankar-Aguilera S, Diomande D, Zupan-Simunek V, Boileau P. Natural evolution of patent ductus arteriosus in the extremely preterm infant. Arch Dis Child Fetal Neonatal Ed. (2015) 100:F558. doi: 10.1136/archdischild-2014-306339 
63. Semberova J, Sirc J, Miletin J, Kucera J, Berka I, Sebkova S, et al. Spontaneous closure of patent ductus arteriosus in infants $</=1500 \mathrm{~g}$. Pediatrics. (2017) 140:e20164258. doi: 10.1542/peds.2016-4258

64. Sellmer A, Bjerre JV, Schmidt MR, McNamara PJ, Hjortdal VE, Host B, et al. Morbidity and mortality in preterm neonates with patent ductus arteriosus on day 3. Arch Dis Child Fetal Neonatal Ed. (2013) 98:F50510. doi: 10.1136/archdischild-2013-303816

65. Velazquez DM, Reidy KJ, Sharma M, Kim M, Vega M, Havranek T. The effect of hemodynamically significant patent ductus arteriosus on acute kidney injury and systemic hypertension in extremely low gestational age newborns. J Matern Fetal Neonatal Med. (2019) 32:320914. doi: 10.1080/14767058.2018.1460349

66. Benitz WE. Learning to live with patency of the ductus arteriosus in preterm infants. J Perinatol. (2011) 31 (Suppl. 1):S42-8. doi: 10.1038/jp.2010.175

67. Bell EF, Acarregui MJ. Restricted versus liberal water intake for preventing morbidity and mortality in preterm infants. Cochrane Database Syst Rev. (2008) 1:CD000503. doi: 10.1002/14651858.CD000503.pub2

68. Bell EF, Warburton D, Stonestreet BS, Oh W. Effect of fluid administration on the development of symptomatic patent ductus arteriosus and congestive heart failure in premature infants. N Engl J Med. (1980) 302:598604. doi: 10.1056/NEJM198003133021103

69. Kim SM, Lee EY, Chen J, Ringer SA. Improved care and growth outcomes by using hybrid humidified incubators in very preterm infants. Pediatrics. (2010) 125:e137-45. doi: 10.1542/peds.2008-2997

70. Park JH, Chang YS, Sung S, Ahn SY, Park WS. Trends in overall mortality, and timing and cause of death among extremely preterm infants near the limit of viability. PLoS ONE. (2017) 12:e0170220. doi: 10.1371/journal.pone.0170220

71. Sung SI, Ahn SY, Seo HJ, Yoo HS, Han YM, Lee MS, et al. Insensible water loss during the first week of life of extremely low birth weight infants less than 25 gestational weeks under high humidification. Neonatal Med. (2013) 20:51-7. doi: 10.5385/nm.2013.20.1.51

72. Green TP, Thompson TR, Johnson DE, Lock JE. Furosemide promotes patent ductus arteriosus in premature infants with the respiratory-distress syndrome. N Engl J Med. (1983) 308:743-8. doi: 10.1056/NEJM198303313081303

73. Gonzalez A, Sosenko IR, Chandar J, Hummler H, Claure N, Bancalari E. Influence of infection on patent ductus arteriosus and chronic lung disease in premature infants weighing 1000 grams or less. J Pediatr. (1996) 128:4708. doi: 10.1016/S0022-3476(96)70356-6

74. Kim JK, Chang YS, Sung S, Ahn SY, Park WS. Trends in the incidence and associated factors of late-onset sepsis associated with improved survival in extremely preterm infants born at 23-26 weeks' gestation: a retrospective study. BMC Pediatr. (2018) 18:172. doi: 10.1186/s12887-018-1130-y

75. Hwang JH, Choi CW, Chang YS, Choe YH, Park WS, Shin SM, et al. The efficacy of clinical strategies to reduce nosocomial sepsis in extremely low birth weight infants. J Korean Med Sci. (2005) 20:17781. doi: $10.3346 / \mathrm{jkms} .2005 .20 .2 .177$

Conflict of Interest: The authors declare that the research was conducted in the absence of any commercial or financial relationships that could be construed as a potential conflict of interest.

Copyright (C) 2020 Sung, Chang, Ahn, Jo, Yang and Park. This is an open-access article distributed under the terms of the Creative Commons Attribution License (CC $B Y)$. The use, distribution or reproduction in other forums is permitted, provided the original author(s) and the copyright owner(s) are credited and that the original publication in this journal is cited, in accordance with accepted academic practice. No use, distribution or reproduction is permitted which does not comply with these terms. 